\title{
Fetal Differentiation of the Lower Respiratory Tract of the One Humped Camel (Camelus Dromedarius): Gross Observation
}

\author{
Bello $\mathrm{A}^{1 *}$, Onu JE${ }^{1}$, Onyeanusi $\mathrm{BI}^{2}$, Umaru $\mathrm{MA}^{3}$, Suleiman $\mathrm{MH}^{2}$, \\ Nzalak J02 and Atabo SM1 \\ ${ }^{1}$ Department of Veterinary Anatomy, Usmanu Danfodiyo University, Nigeria \\ 2Department of Veterinary Anatomy, Ahmadu Bello University Zaria, Nigeria
}

${ }^{3}$ Department of Theriogenology and Animal production, Usmanu Danfodiyo University, Nigeria

\section{Research Article \\ Volume 1 Issue 3}

Received Date: November 14, 2017

Published Date: December 11, 2017

*Corresponding author: Dr. A Bello, Department of Veterinary Anatomy, Usmanu Danfodiyo University, Sokoto, Nigeria, Tel: +234(0)8039687589; E-mail: abccrcfge28@gmail.com

\section{Abstract}

A study involving gross differentiation was conducted on the lower respiratory tract of 52 foetuses of the one-humped camel collected from the Sokoto metropolitan abattoir, over a period of five months at different gestational ages. Sex differences were not taken into consideration. The approximate age of the fetuses was estimated from the crown vertebral rump length (CVRL) and samples were categorised into first, second and third trimester. Observation of the trachea reveals the division in to cervical and thoracic part in all the stages of development (early, middle and late). At first trimester, the cervical trachea is located along the ventral midline of the cervical region with the esophagus lying dorsal and to the left. The cervical part of trachea was observed to have been covered ventrally by the right and left sternohyoideus muscles and laterally by the sternothyroideus muscles in all the stages of development. The trachea continues to increase in size, shape and diameter resembling adult camel from the early third trimester of age. The tracheal cartilages were observed to appear at the late first trimester. They are c-shaped and incomplete dorsally with the ends of the tracheal cartilages joined by smooth muscle (musculus trachealis) in all the stages of development. The tracheal rings ends meeting of the right end with the left end between the trachealis muscles, the carotid sheath is dorsolateral to the trachea from early second trimester to late third trimester of age.

Keywords: Camel; Gross; Trachea; Lungs; Morphology

Abbreviations: CVRL: Crown vertebral rump length

\section{Introduction}

Camels are in the taxonomic order Artiodactyls (eventoed ungulates), sub order Tylopoda (pad-footed), and Family Camelidae [1]. They are pseudo-ruminants that possess a three-chambered stomach, lacking the omasum that is part of the four-chambered stomach of the order Ruminantia [2,3]. The true camels (Camelus dromedarius and Camelus bacterianus) are closely related anatomically to the South American Camelids (Llama, Alpaca, Vicuna and Guanaco) [4]. 
The respiratory system plays a vital role in thermoregulation, the sense of smell, and voice are associated with it. In birds the respiratory system differ from mammals due to specific structures includes nasal cavity, larynx, trachea, syrinx, bronchi, lungs and air sacs, while in mammals the respiratory system consist of nostrils, nasal cavity, larynx, trachea, bronchi, lungs. In birds the trachea bifurcation at the syrinx to the right and left primary bronchi, both enter the target lungs via the hilus at septal surface as a primary bronchus.

The respiratory organs play crucial role in the phylogeny of vertebrates. The changes in respiratory organs lead to the correlative changes of the whole organism. The lower respiratory tract consists of the larynx, the tracheobronchial system and the right and left lungs. The two parts of the lung are divided from each other by the content of the mediastinum. Embryologically in bovine, the first indication of the future lower respiratory system appears in the $4 \mathrm{~mm}$ embryo, in the primitive pharyngeal floor just behind the pharyngeal pouches, early in week 4 of embryonic life, as a longitudinal groove called the laryngotracheal groove.

There have been many studies involving the gross morphology and histology of the various systems in adult camel but detailed studies have not been conducted on the developmental changes of the lower respiratory tract of the camel fetus [3,5-8]. Though much work appears to have been done on the physiology and morphology of the brain, on the heart, on salivary glands); on the digestive tract, on female reproductive organ, on foot disorder, on hump attachment, and on anatomy of reproductive tract, there is dearth of information on the fetal changes of the lower respiratory tract of the one-humped camel [1,7-13]. The anatomical basis of inspiration, expiration and gaseous exchange, especially those activities that are essential for the survival of the animal under extreme harsh conditions

\section{Materials and Methods}

\section{Study Area}

The research was conducted in Sokoto state which is located to the northwest of Nigeria between latitudes $12^{\circ} 0 \mathrm{~N}$ and $130^{\circ} 54 \mathrm{~N}$ and between longitudes $40^{\circ} 8 \mathrm{E}$ and $60^{\circ}$ 54E. The State ranks second in the nation's livestock population with an estimated livestock population of 43,960 camels, 3 million cattle, 3 million sheep and 5 million goats.

\section{Source of Samples}

Complete respiratory systems of camel fetuses were used for the study. Samples were sourced from Sokoto metropolitan abattoir, and transported to the Anatomy Research Laboratory of the Department of Veterinary Anatomy, Usmanu Danfodiyo University, Sokoto (UDUS).

\section{Experimental Design}

The study involves an evaluation of the dromedary trachea using the fetuses at various gestational ages. Camel fetal wastages were collected from Sokoto metropolitan abattoir and used for the research. The recovered fetuses were taken to the Veterinary Anatomy Laboratory, Usmanu Danfodiyo University Sokoto and aged by the method adopted by El-Wishy, et al [14].

\section{Ageing of the Fetus}

The ages of the fetuses were estimated biometrically using the formula [GA \pm (CVRL + 23.99)/0.366] as described by El-Wishy, et al. [14], where GA is the gestational age (in days). This was conducted by taking the weights of the fetuses using a beam balance. With the aid of a rule (butterfly), the crown vertebral-rump length (CVRL) was measured from the caudal fontanel to the base of the tail, following the vertebral curvature.

The fetuses were categorized into definite trimesters using the calculated gestational ages and other gross features (developmental horizon) as described (Table 1).

\begin{tabular}{|c|c|c|}
\hline First trimester & $(1-130$ days $)$ & \\
\hline Early first trimester (EFT) & $(1-42$ days) & 6weeks \\
\hline Middle first trimester (MFT) & $(43-85$ days $)$ & 6weeks \\
\hline Late first trimester (LFT) & $(86-130$ days) & 6weeks \\
\hline Second trimester & $(131-270$ days $)$ & \\
\hline Early second trimester (EST) & $(131-175$ days) & 6weeks \\
\hline Middle second trimester (MST) & $(176-220$ days $)$ & 6weeks \\
\hline Late second trimester (LST) & $(221-270$ days) & 6weeks \\
\hline Third trimester & $(271-390$ days $)$ & \\
\hline Early third trimester (ETT) & $(271-310$ days) & 6weeks \\
\hline Middle third trimester (MTT & $(311-350$ days) $)$ & 6weeks \\
\hline Late third trimester (LTT) & (350 - 390 days) & 6weeks \\
\hline
\end{tabular}

Table 1: Calculation of trimesters using Gestational ages

\section{Sample Size}

The sample size was based on the accidental findings of the wasted fetuses. A total of fifty-four (54) fetuses were used for the research and categorized as follows (Table 2). 


\begin{tabular}{|c|c|}
\hline First trimester & $\mathbf{1 8}$ fetuses \\
\hline Early first trimester & (6 fetuses) \\
\hline Middle first trimester & (6 fetuses) \\
\hline Late first trimester & (6 fetuses $)$ \\
\hline Second trimester & $\mathbf{1 8}$ fetuses \\
\hline Early second trimester & (6 fetuses $)$ \\
\hline Middle second trimester & (6 fetuses $)$ \\
\hline Late second trimester & (6 fetuses $)$ \\
\hline Third trimester & $\mathbf{1 8}$ fetuses \\
\hline Early third trimester & (6 fetuses $)$ \\
\hline Middle third trimester & (6 fetuses $)$ \\
\hline Late third trimester & (6 fetuses $)$ \\
\hline
\end{tabular}

Table 2: Categorized 54 fetuses.

\section{Dissection of the Fetuses}

The method was adopted for the dissection of the fetuses. This was done by placing the fetuses on dorsal recumbency and making a mid-ventral skin incision (linea alba) at abdomino-pelvic region, through the thoracic region and up to the neck at the inter-mandibular space. The entire trachea was dissected out, identified and the morphometric values were recorded.

\section{Experimental Design of the Study}

The entire study was divided into four different segments as adopted by Tefera.

Trachea

* Gross observation

- Shape

- Weight

- Length

- Width

- Volume

Morphological Studies of the Lower Respiratory Tract

During the course of the study, each separate segment of the tract was observed for gross features. These segments included trachea, bronchi, bronchioles and lungs. These organs were thoroughly observed grossly, both internally and externally.

\section{Results}

\section{Trachea}

Observation of the trachea reveals the division in to cervical and thoracic part in all the stages of development (early, middle and late). At first trimester, the cervical trachea is located along the ventral midline of the cervical region with the esophagus lying dorsal and to the left as shown in Figure 1. The cervical part of trachea was observed to have been covered ventrally by the right and left sternohyoideus muscles and laterally by the sternothyroideus muscles in all the stages of development (Figure 11). The trachea is directed caudally from cricoidal cartilage of the larynx at the level of the second cervical vertebrae at early second trimester to the level of the fourth ribs in (thoracic vertebra) in the late third trimester as shown in (Figure 1-2). After passing through the thoracic inlet, the thoracic part of the trachea continues caudally along the dorsal midline and terminates at the tracheal bifurcation (bifurcation tracheae). The trachea became more prominent and maintains its orientation to the esophagus similar to that in the cervical region in both second and third trimester of age (Figure 1). The trachea bifurcates dorsal to the base of the heart at the level of the third intercostals space into the right and left principal bronchi at the middle second trimester (Figure 5). The trachea continues to increase in size, shape and diameter resembling adult camel from the early third trimester of age as shown in Figures 2-10.

The tracheal cartilages were observed to appear at the late first trimester. They are c-shaped and incomplete dorsally with the ends of the tracheal cartilages joined by smooth muscle (musculus trachealis) in all the stages of development. The tracheal rings ends meeting of the right end with the left end between the trachealis muscles, the carotid sheath is dorsolateral to the trachea from early second trimester to late third trimester of age (Figures 210).

\section{Bronchus}

Observations show that the trachea is divided into right and left principal bronchi right from the early first trimester. The right principal bronchi then continuous as the lobar bronchi given rise to the division of cranial (Apical), middle and the caudal lobe while the left principal bronchi give rise to cranial (Apical) and the caudal lobe from the middle first trimester to late third trimester (Figure 11). The division is not pronouncing in the early first trimester due to the absence of clear external demarcation (Figure 1). The right and left principal bronchi arises the right lobar bronchi and left lobar bronchi. The last one divided into segmental bronchi for each side and sub segmental bronchi with advancement in gestation from the middle second trimester to late third trimester of age (Figures 5-19). This followed by regular branching to form the bronchiole. The bronchiole tree is composed of each the lobar bronchi give off bronchioles and classified the bronchioles into the dorsal and ventral bronchiole. The right apical lobe is formed by first bronchi of the dorsal bronchi (directed dorsally).The right middle lobe is formed by first bronchi of the lateral bronchi (directed 
ventrally). The caudal lobar bronchi are formed by medial bronchiole as in Figure 7. In the left apical lobar bronchi is formed by the first bronchiole of the lateral bronchiole (directed laterally). The bronchioles of the dorsal, ventral and medial bronchiole constitute the left caudal lobe bronchi as in (Figure 10).

\section{Lungs}

The observed anatomical description of the camel fetal lung is cone shape, which had apex and three surfaces; costal, medial and diaphragmatic surface in all the stages of development (Figures 1 \& 2). Each lung is divided by shallow fissure into distinct lobe from the middle first trimester to late third trimester of age (Figures 2-9) with no clear distinguishing fissure in the early first trimester (Figure 1).

The lungs were observed to be pale red in color at early first trimester to early second trimester (Figure 1 to 4 ). This colour changes to bright red colour at the middle of second trimester to the end of gestation (Figures 5-9). This completely surrounds the heart as in Figure 1. The shape of the lung in situ was in conformity with the shape of the thoracic cavity in all the stages of development (Figures 1-9).

The lung borders were observed to have dorsal, ventral and caudal borders in all the stages of development as in Figures 1-5. The dorsal border is rounded and thick in all the stages of development (Figure 3). The ventral border is flattened and rounded in all the stages of development (Figure 3). The caudal (basal) border is sharp and pointed in all the stages of development as in Figure 4. The costal surface of lung is smooth and convex right from the middle first trimester (Figure 2). The costal surface is neared with lateral thoracic wall and present of impression of ribs (Figure 5). Whereas, the medial or mediastinal surface is the narrowest surface consists of heart region and its pericardium and it contains the cardiac impression and passage of large blood vessels and nerve fibers entering or leaving lung through the hilus in all the stages of development (Figures 3 and 9). The diaphragmatic surface corresponds with the shape of the diaphragm in all the stages of development (Figures 1-9).

The right lungs were observed to have three lobes separated by complete fissures from the middle first trimester to late third trimester of age (Figures 2-9). Each of the lobes has an independent hilus. The hila of each of these lobes collectively from the main hilus of right lung (Figure 6). Also the right lungs were large organs which occupy most the right thoracic cavity from the middle first trimester to late third trimester of age (Figures 1-9).
The left lungs were observed to have divided into two distinct lobes by shallow fissure at the heart level from the middle first trimester to late third trimester of age. The left lung lobes were observed to constitute the left apical lobe and caudal lobe (diaphragmatic lobe) as in Figures 4-9.
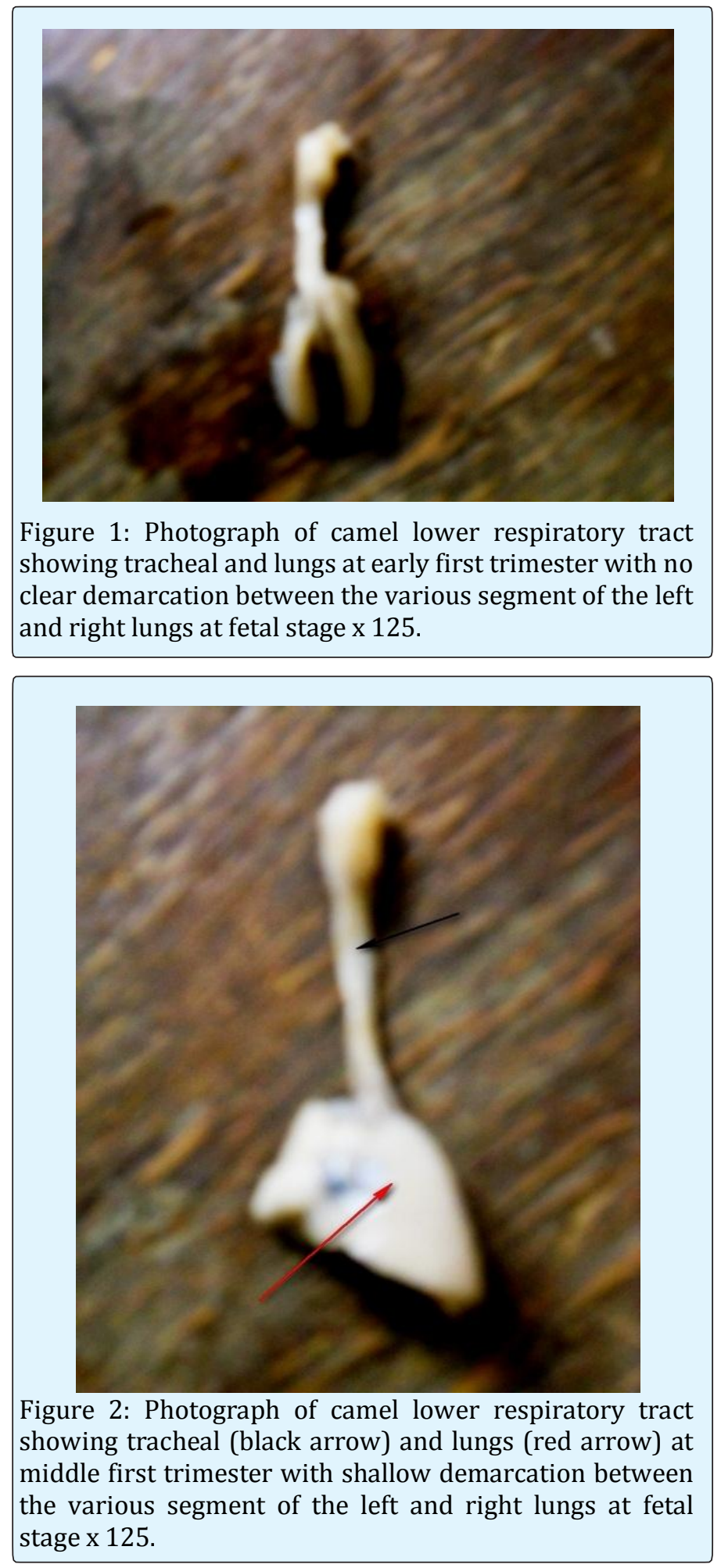


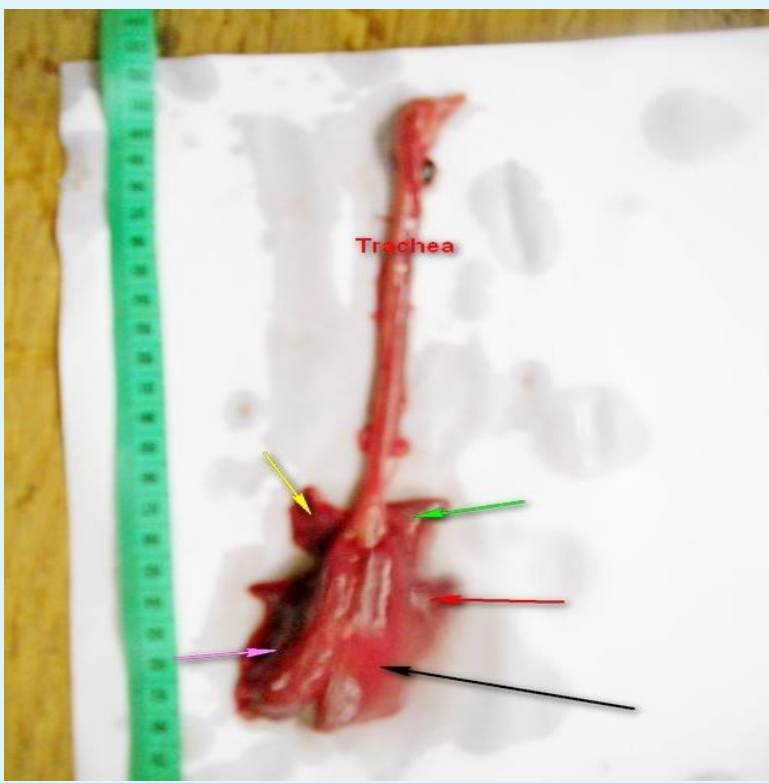

Figure 3: Photograph of camel lower respiratory tract showing tracheal and lungs of camel at late first trimester with clear demarcation between the various segment of the left lung ; left apical lobe (yellow arrow) and left caudal lobe (pink arrow) and right lung ; right apical lobe (green arrow), right middle lobe(red arrow) and right caudal lobe(black arrow) with visible cardiac notch by the left lung x125.

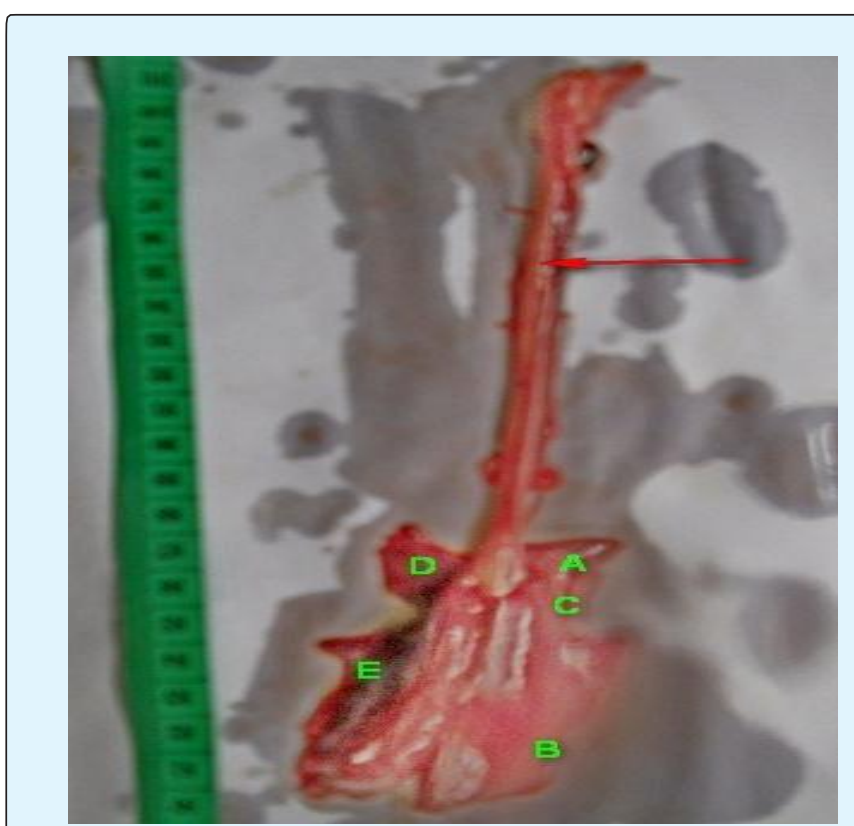

Figure 4: Photograph of camel lower respiratory tract showing tracheal and lungs of camel at early second trimester with clear demarcation between the various segment of the left lung ; left apical lobe (D) and left caudal lobe (E) and right lung ; right apical lobe (A), right middle lobe (C) and right caudal lobe(B), x125.

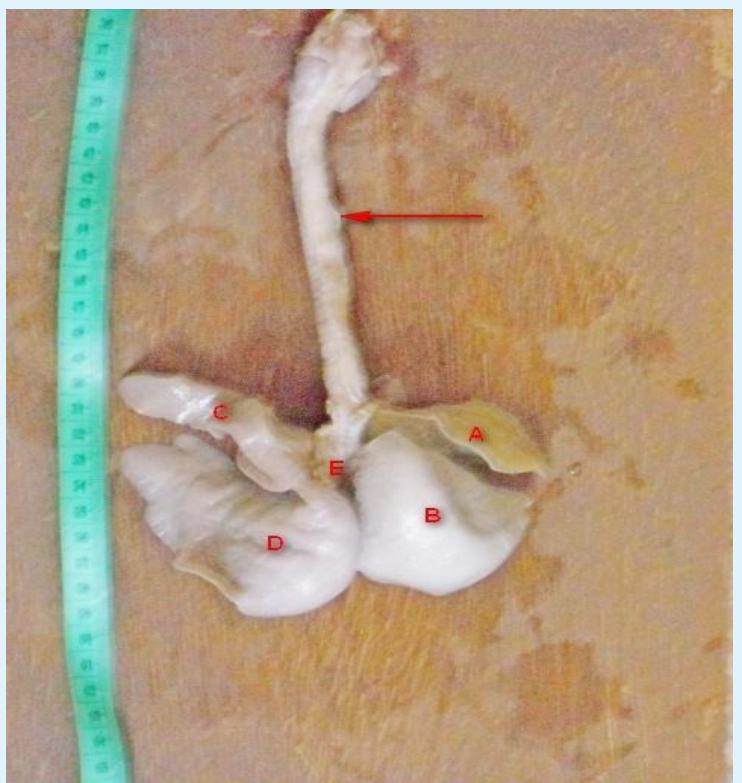

Figure 5: Photograph of camel lower respiratory tract showing tracheal and lungs of camel at middle second trimester with clear demarcation between the various segment of the left lung ; left apical lobe (A) and left caudal lobe (B) and right lung ; right apical lobe (C), right middle lobe and right caudal lobe(D), Tracheae Bifurcation (carina)(E) x 125 .

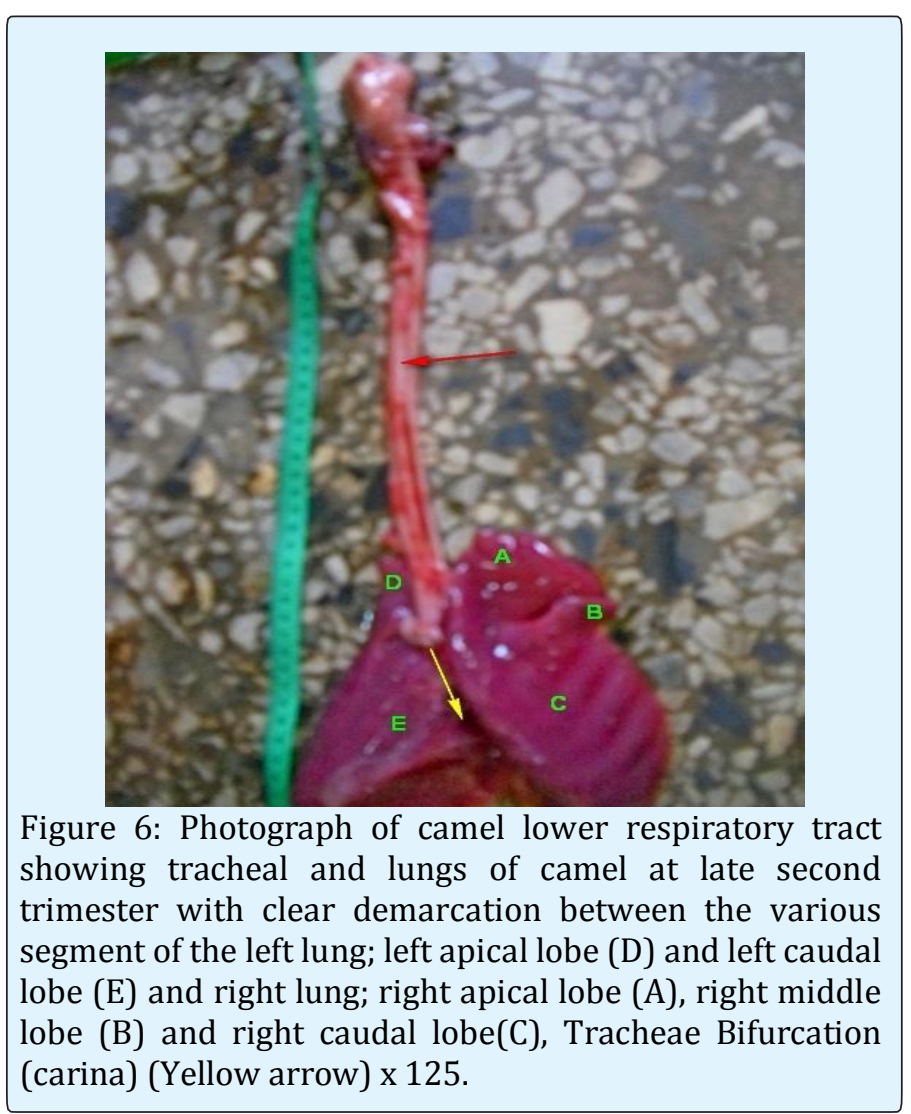




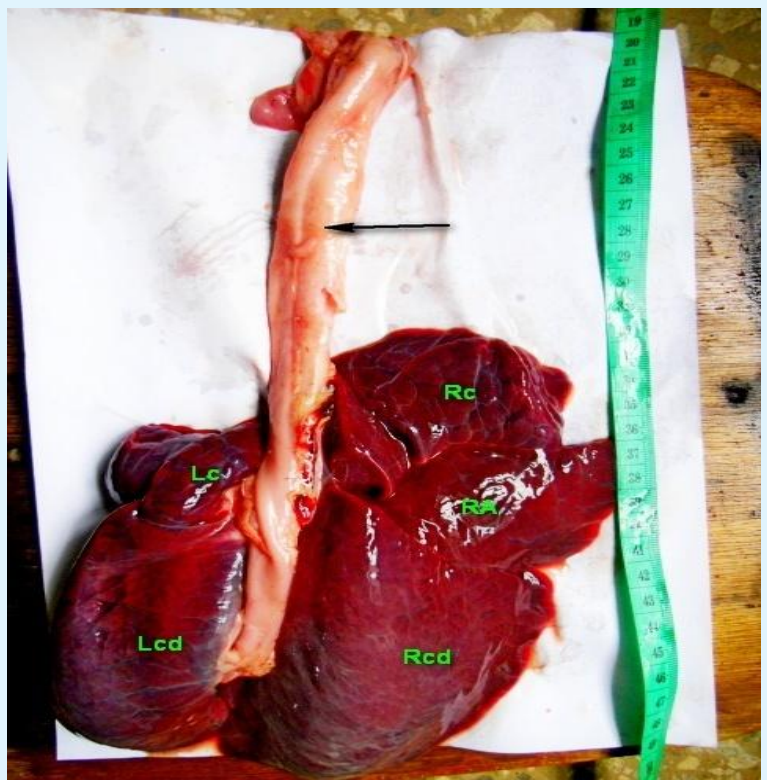

Figure 7: Photograph of camel lower respiratory tract showing tracheal and lungs of camel at early third trimester with clear demarcation between the various segment of the left lung; left apical lobe (Lc) and left caudal lobe (Lcd) and right lung ; right apical lobe (Rc), right middle lobe $(\mathrm{Ra})$ and right caudal lobe(Rcd) x 125 .

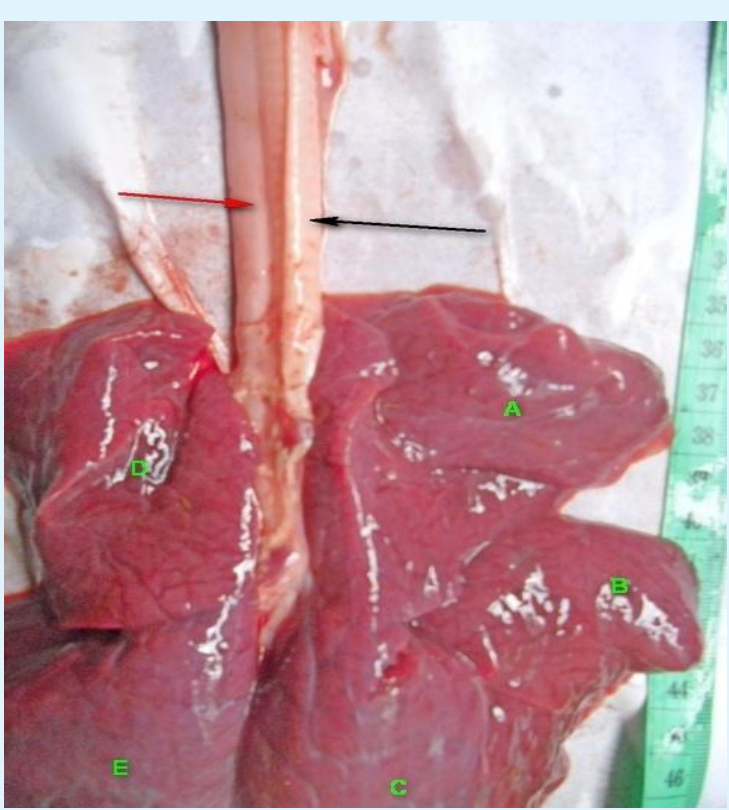

Figure 8: Photograph of camel lower respiratory tract showing tracheal and lungs (Black arrow), esophagus (Red arrow) and Lungs of Camel at middle third trimester with clear demarcation between the various segment of the left lung; left apical lobe (D) and left caudal lobe (E) and right lung; right apical lobe (A), right middle lobe (B) and right caudal lobe(C) x 125 .

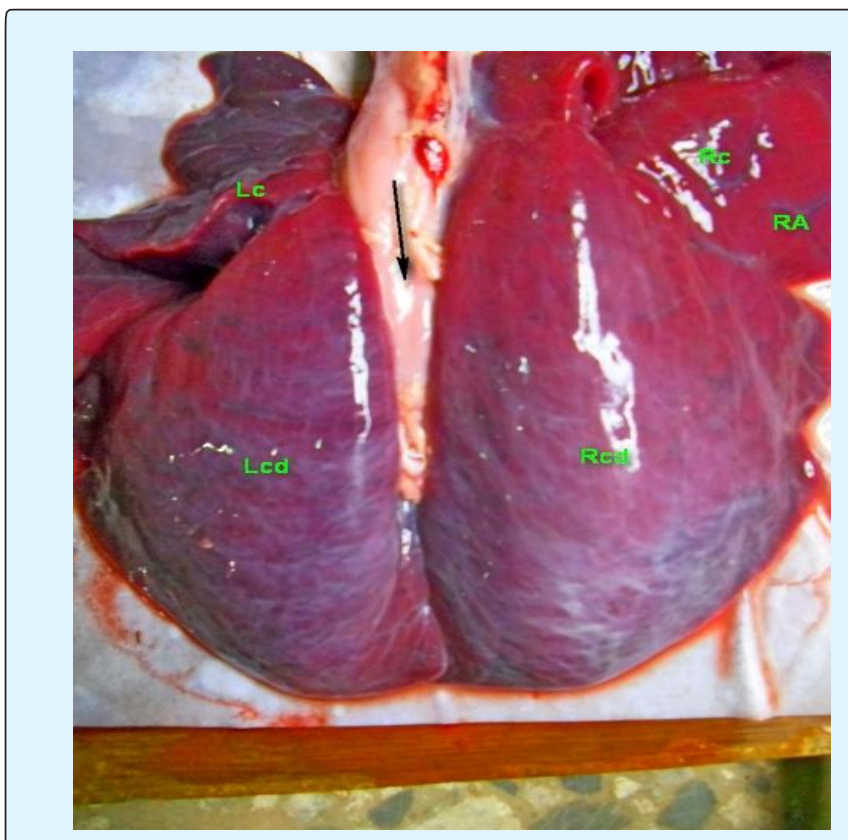

Figure 9: Photograph of camel lower respiratory tract showing tracheal and lungs at late third trimester with clear demarcation between the various segment of the left lung; left apical lobe (Lc) and left caudal lobe (Lcd) and right lung; right apical lobe (Rc), right middle lobe (Ra) and right caudal lobe (Rcd) x 125 .

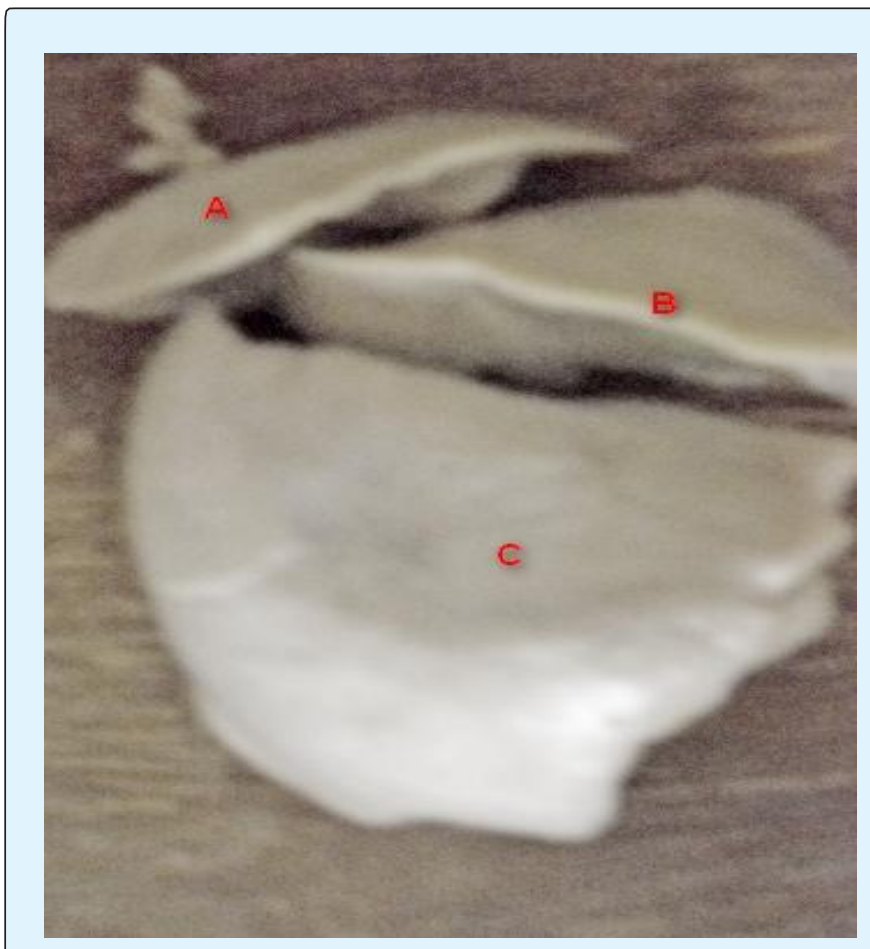

Figure 10: Photograph of camel right lungs at middle third trimester showing clear demarcation between the various segment of the right apical lobe (A), right middle lobe (B) and right caudal lobe(C) $\times 125$. 


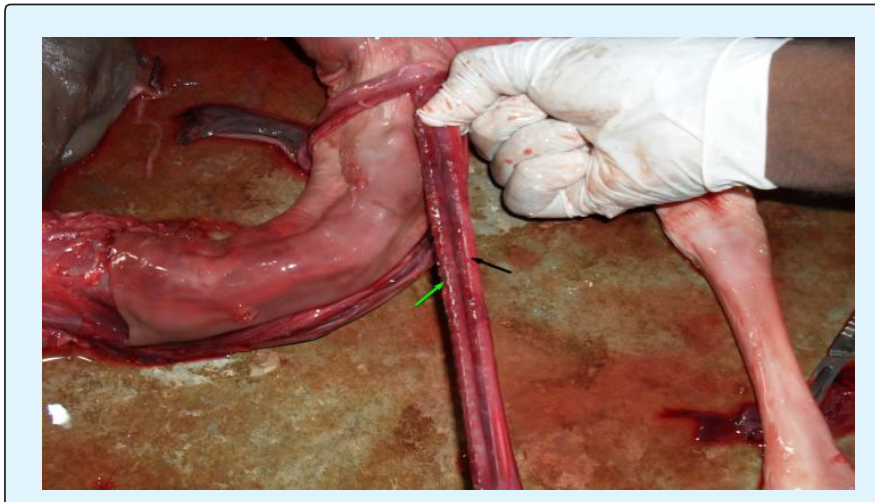

Figure 11: Camel fetus at late second trimester showing the position and relation of the trachea (green arrow), jugular vein (blue arrow), associated muscles and esophagus (black arrow) at fetal stage x 125 .

\section{Discussion,} Conclusion and

\section{Recommendation}

The observed increase in weight, length and diameter of various segments of the lower respiratory tract in the study is in line with the findings of bovine, porcine and caprine specie by Bal and Ghoshal, and Georgieva and Gerov respectively $[15,16]$. The lower respiratory tract indices observed in the study showed significant difference in relation to the age $(\mathrm{P} \leq 0.05)$ and the indices were decreasing with advancement in gestation (body development) and similar developments were seen in the study of Georgieva and Gerov, Bal and Ghoshal in porcine species $[16,17]$.

The progressive increase in weight, length, width and diameter of the trachea and lungs based on gestation period is in line with the observations on the trachea of human and showed to have significant difference in relation to the age $(P \leq 0.05)[18,19]$. The observed increase in lengths and widths of the trachea and lungs in this study showed to have significant difference in relation to the age $(\mathrm{P} \leq 0.05)$ and is in line with the observations. Who study the developmental anatomy of red deer trachea based on gestational period [19-21].

A geometrical increase in volume of the various segments of trachea, left lungs and right lungs as observed in this study showed to have significant difference $(\mathrm{P} \leq 0.05)$ with advancement in gestation and was in line with the findings of porcine, bovine, buffalo and Llama [11,18,21].

\section{Trachea}

The division the trachea into cervical and thoracic part early in life (early first trimester) throughout the stages of development is in line with the size and location of the organ similar observation were seen in sheep, goat, pig and cattle.

The observed turned shape appearance of the trachea at early, middle and late first trimester and change to tube like appearance at second and third trimester shown that during development the trachea diameter keep on increasing in cranio-caudal direction. But mention its size and shape at certain stages of development. This stages of constant size and shape was found to be at middle second trimester of stage.

The appearance of the trachea base on size shown that at first trimester it appears to be cranio-caudal flatten but cylindrical at early second trimester end of gestation. This finding is in time with that of West Africa goat, Mongolian goat and cattle. Add that in the course of development of tubular organ, the laminar diameter tend to increase in cranio-Caudal direction.

The observed C-shape (incomplete) cartilaginous ring of the trachea begin to appear at late first trimester of age, with an appearance of a musculo-membrane tube in both early and middle trimester shown that in the development of trachea, cartilage is form at certain stage of gestational period. The present study was in agreement with the findings of cat. Human and dog [15]. Added that the development of trachea wall follows a patent of five stages (mesenchyme stage, connective tissue stages, premature chondrocyte stage and mature chondrocyte Stage). However, in the study, all the stages were observed.

\section{Bronchus}

The observed division of the bronchus into right and left principle bronchus from early first trimester is in line with the findings in goat and feline specie from the research, it was observed that the camel bronchus was small or no meaningful size. Similar observation were seen in sheep, goat, pig and cattle [17,22-24].

Further division and branching of the bronchus of the bronchus of the right and left lungs lobes start from the middle first trimester in this species of animal. This finding is in time with that of West Africa goat, Mongolian goat and cattle. Said that, in the course of development of tubular organ, the laminar diameter tend to decreasing in cramio-Caudal direction [25-30].

Observation from the result shown that, at early first trimester, the fetal lungs were cone shape, with clear demarcation of apex and base, indicate that the lungs have no specific shape but obey the shape of the thoracic 
cavity. This is in line with the finding on gross features of red Sokoto goat. And mangolian goat by Sukon shown that the shape the lungs of red Sokoto goat insitu correspond to the shape of the thoracic cavity [8,30-33].

Observation shown that early first trimester there was no clear demarcation to differentiate the different lobes of the lungs as shown in tables 1 and 2 . This is an indication that the demarcation of camel lungs into various segment (criminal, middle and caudal lobe of the right and left lungs start at middle first trimester of age.

The observed change in colour of the lungs from pale red to bright red as shown in Figure 11 to Figure 10 shown that at early stage of development (first trimester) the lungs have poor vascularisation hence the pale colour. While at the period of progressive development, with increase in gestational age, development of blood vessels progresses hence the colour change to bright red.

The observed distinct borders of the lungs early in the development (early first trimester) with clearly and prominently with advancement in gestational age prove to shown that prenatal development is progressively in succession.

* The trachea appeared to be as a tunnel with two openings. The cranial diameter is greater than the caudal (thoracic) pant of the trachea in all the stages of development. The diameter of the trachea was shown to be increasing with advancement in gestation. The diameter of the trachea is greater than that of the bronchus right from the early second trimester; with no difference all the stages of first trimester.

* The trachea of camel tends to be circular in shape with muscular gap at the dorsal wall right from late first trimester of age. Fusion of the cartilage rings was not observed in any region and at all stages of development.

* The observed anatomical description of the camel fetal lung is cone shape, which had apex and three surfaces; costal, medial and diaphragmatic surface in all the stages of development

* The lungs did not show any external division at early first trimester but at middle first trimester to end of gestation

* The right lungs are heavier than the left lungs right from the middle of the first trimester of age. The right lungs were observed to have three lobes separated by complete fissures from the middle first trimester to late third trimester of age. Each of the lobes has an independent hilus
* The left lungs were observed to have divided into two distinct lobes by shallow fissure at the heart level from the middle first trimester to late third trimester of age. The left lung lobes were observed to constitute the left apical lobe and caudal lobe (diaphragmatic lobe)

* The bronchi of camel are indented in the lungs compared to other species of domestic animals.

\section{References}

1. Bello A, Onyeanusi BI, Sonfada ML, Adeyanju JB, Umaru, et al. (2012) Histomorphological Studies of the Prestiatal Development of Oesophagus one hump camel (Camelus) dromedaries). Scientific journal of Agricultural 1(14): 100- 104.

2. Sonfada ML (2008) Age related changes in musculoskeletal Tissues of one-humped camel (Camelus dromedarius) from foetal period to two years old. A Ph.D Thesis, Department of Veterinary Anatomy, Faculty of Veterinary Medicine, Usmanu Danfodiyo University, Sokoto, Nigeria.

3. Bello A, Onyeanusi BI, Sonfada ML, Adeyanju JB, Umaru MA (2012) A biometric study of the digestive tract of one-humped camel (Camelus dromedarius) foetus. Science journal Zoology 1(1): 11-16.

4. Malie M, Smuts S, Bezuidenhout (1987) Anatomy of the dromedarius camel. Clarenden press, Oxford.

5. Marzook MA (1996) Dilatation of the Cervix During the Peripaturient Period in the Camel (Camelus dromedaries). J of Camel Practice and Research 3(2):133-137.

6. Reece WO (1997) Physiology of domestic animals. Williams and Wilkins. Pp: 464.

7. Ghaji A, Lakshminarasimhan A, Ema AN, Aliu YO (1982) The Brain of the One-Humped Camel (Camelus dromedaries) Form and Structure. Nig Vet Jour 11(1): 90-96.

8. Sukon P (2009) The Physiology and Anatomy of the Digestive tract of Normal Llamas. PhD Thesis, Oregon State University, Corvallis.

9. Ghaji A, Luga II, Tulule SS (1989) The Conducting System of the Heart of the One-Humped Camel(Camelus dromeraius L.). Zariya Veterinarian 4(1):53-55.

10. Yagil R (1985) The Desert Camel: Comparative Physiological Adaptation. Comparative Animal Nutrition, Vol 5, Basel (Switzerland). 
11. Asari M, Oshige H, Wakui S, Fukaya K, Kano Y (1985) Histological development of bovine abomasus. Anat Anz 159(1-5): 1-11.

12. Murray EF (1997) Evolutionary History and Differences between Camelids and Ruminants. Journal of Camel Practice and Research 4(2): 99-105.

13. Gopal S, Gahlot TK (1997) Foot Disorders in Camels ( Camelus dromedaries ). J Camel Pract Res 4(2): 145154.

14. El-Wishy AB, Hemeida AB, Omer MA, Mubarak AM, ElSyaed MA (1981) Functional changes in the pregnant camel with special reference to fetal growth. Br Vet J 137(5): 527-537.

15. Luciano L, Voss-wermbter G, Behnke M, Engelhardt WV, Reale E (1979) Die Struktur der Magenschleeimhaut beim Lama (Lama guanacoe and Lama lamae) I. Vormägen Gegenbauers Morphol Jahrb 125: 519-549.

16. Georgieva R, Gerov K (1975) The morphological and functional differentation of the alimentary canal of pig during ontogeny. I. Development and differentation of the fundic portion of the stomach. Anat Anz 137(1-2): 12-15.

17. Bal HS, Ghoshal NG (1972) Histomorphology of the torus pyloricus of the domestic pig (Sus scrofa domestica). Zbl Vet Med C 1(4): 289-298.

18. Belknap EB (1994) Medical problems of llamas. In: The Vet. Cl. of North America Food Animal Practice, Update on Llama Medicine. Johnson, LW (Editor). Philadelphia, WB Saunders Co.

19. Franco A, Robina A, Regodón S, Vivo JM, Masot AJ, et al. (1993b) Histomor-phometic analysis of the omasum of sheep during development. American J Vet Res 54: 1221-1229.

20. Franco A, Robina A, Guillén MT, Mayoral AI, Redondo E (1993a) Histomor-phometric analysis of the abomasum of sheep during development. Ann Anat 175: 119-125.

21. Franco A, Robina A, Regodón S, Vivo JM, Masot AJ, et al (1993c) Histomor-phometric analysis of the reticulum of the sheep during development. Histol Histopathol 8: 547-556.

22. Bello JE, Onu ML, Sonfada SA, Shehu MI; Jimoh et al (2014) Histomorphological Studies Of The Prenatal Development Of Thyroid Gland In One Humped Camel
(Camelus dromedarius). JBR Journal of Clinical Diagnosis and Research 2(1): 1-3.

23. Bello A, Alimi 00, Sonfada ML, Umaru MA, Onu JE, et al (2014) Histomorphometric Study of the Prenatal Development of the Circumvallate Papillae of OneHumped Camel (Camelus Dromedarius). Anat \& Physiol 4.

24. Bello A, Dabai DI, Umaru MA, Shehu SA, Jimoh MI (2016) Prenatal Development of Yankasa Sheep (Ovis aries) Kidney: A Histomorphometric Study. J Kidney 2: 126 .

25. Bello A, Onyeanusi BI, Sonfada ML, Adeyanju JB, Umaru MA, et al (2014) Gross Embryonic Diffrentiation of the Stomach of the One Humped Camel (Camelus dromedarius). Anat \& Physiol 4: 131.

26. Bello A, Lawal UF, Onyeanusi BI, Sonfada ML, Umaru MA, et al (2013) Prenatal Development of the Kidney of One-Humped Camel (Camelus dromedarius) - A Histomorphometric Study; African Journal of Biomedical Research 16(1): 31-37.

27. Bello A, Umar AA, Sonfada ML, Umaru MA, Shehu SA, et al (2013) Estimation of camel age in nigeria using rostral dentition. In the Proceeding of $38^{\text {th }}$ Conference of the Nigerian society for Animal production, and $40^{\text {th }}$ Anniversary Annual conference 2(1): 34-40.

28. Bustinza AV (1979) South American Camelids. In: IFS Symposium Camels. Sudan, pp: 73-108.

29. Franco A, Masot AJ, Gómez L, Redondo E (2004) Morphometric and immuno histochemical study of the rumen of red deer during prenatal development. Journal of Anatomy 204(6): 501-513.

30. Hartley JB (1999) Camels in the Horn of Africa. In: IFS Symposium Camels. Sudan, pp: 109-124,

31. Khanna ND (1990) An Over View of Work Performance of Camel as Drought and Riding Animal Camel News Letter 7: 87.

32. Mustapha LG, Oluyisi AJ (1993) The status of camel camelus dromedaries as a food animal in the semiarid zone of Nigeria. A paper presented at the $18^{\text {th }}$ Annual Conference of Nigerian Society for Animal Production. Federal University of Technology, Owerri, March 1993.

33. Wilson RT (1978) Studies on the livestock of Southern Darfur. Sudan V. Notes on camels. Trop Anim Health Prod 10(1): 19-25. 